\title{
Changing Educational Landscape from Traditional to Outcomes-based Education in South Korea
}

\author{
Kristine Joy S. Simpao ${ }^{1}$ \\ ${ }^{1}$ Assistant Professor, International Commerce, Keimyung University, South Korea, \\ june3_joy@yhaoo.com
}

\begin{abstract}
This research aimed to identify the role of $\mathrm{OBE}$ in changing the educational landscape through examining the correlation of Outcomes-based Education to student grade, teacher's performance, student knowledge, teacher's extent of experience, and practice of OBE. This study analyzes the role of OBE teaching method in educational change in South Korea as a baseline to develop an education framework as a guide of the department in its readiness for the paradigm-shift to outcomes-based systems model of higher education. The respondents utilized controlled achievement tests, structured questionnaires, student and professor's performance grades, and interview guides in accumulating qualitative and quantitative data from the respondents. The finding denotes that outcomes-based education correlates with student grade, teacher's performance, student knowledge of OBE, teachers' extent of OBE expertise, and teaching method. This result implies that outcomes-based education learning, and assessment approaches are effective mechanisms in improving the student's educational experiences and, at the same time, a useful tool for enhancing South Korea's educational system in modern times. This research implies that the OBE system can assists educators in designing a curriculum to give students the knowledge and skills they need to demonstrate the learning outcomes. The recommends the development and adaptation of an outcome-based framework towards designing research and development-oriented OBE curriculum for the International Commerce Department of Keimyung University.
\end{abstract}

Keywords: Outcomes-based Education, Educational Change, Curriculum Development, Learning Outcomes, OBE Framework

\section{Introduction}

In recent years, the educational system changed in many countries throughout the various era. Schools were devoted to transforming the educational landscape through several strategies like curriculum transformation, e-learning mode, student-centered learning, educational assessment, changing academic policies, and various kinds to achieve improvements. Schools, Universities, and colleges are implementing different strategies to cope-up with similar veering socio-economic trends. Higher education mainly creates a dramatic seismic change on fissures in technology and institutions' technical organization.

Curriculum reformation is conceding as a critical instrument of educational change. The shift in curriculum content, teaching method, and assessment process is an essential strategy for educational change since 1960. However, several articles argued that school curriculum transformation has only limited results over the longer term.

In the traditional educational approach, teachers dominate the learning process. The student accepts

Received: January 27, 2021; 1st Review Result: March 15, 2021; 2nd Review Result: April 30, 2021 Accepted: May 25, 2021 
whatever directives to do, how they should learn the subjects, and spoon-feed students with overloaded theories . A researcher[1] claimed that traditional education ignores or suppresses learner responsibility. Traditional teaching and learning approaches have a disappointing outcome on students' performance[2]. Research findings confirm that learning becomes more useful to learners when responsibilities and control of the learning process are given. When the learning process focused on students' interests, abilities, and learning styles, the educational approach is called student-centered learning[3].

Educational change is a process that involves considerable negotiation and communication of curriculum development which led to changes in the academic environment. Educational change is a reality of life imperiled by teachers' constant innovation. This strain forces academic institutions to remain persistent in facing this paradox of innovation without change. This statement affirms that in educational research and policy, educational change is one of the significant issues [4]. This issue put schools held accountable to the stakeholders in acting on professional judgment, assessment, discussing various information that can use to make positive changes.

Educational change's initial goal is to improve the school system and academic policy. This improvement starts with principals' and teachers' professional development, student learning, learning conditions, and process[5][6]. Learning outcomes result from students' learning experience that measures if they achieved the academic goal. In other literature, the learning outcome is what the student expects to learn and demonstrate upon completing it[7]. These outcomes are said to be "student achievements," which are the assessment results in numeric letters or adjectives. OBE is an educational element recognized in responding to socio-economic problems in the world of a knowledge-based economy. A study entitled "A Transformational Perspective on Quality and Mobility in Higher Education," the educational institution to show a significant shift toward this new structure to stay globally competitive[8]. A study accentuated the need for comprehensive knowledge and understanding of outcomes-based education to achieve the set objectives and made it functional[9]. The goal now of different higher education institutions is on student's assessment with learning outcomes.

Outcomes-based Education (OBE) has emerged as an essential instructional strategy focusing on collaborative teaching and learning, community immersion, research-based, digital technology learning, and assessment outcomes. It is a learner-centered approach requiring students to validate their knowledge through measurable outputs. Hence, students do things more than knowing something. This educational model has gained increasing support-and attracted scrutiny in recent years. OBE becomes an organizational structure in higher education. It is a way to structure content around activities that lead to demonstrable proficiency of a specific skill, knowledge, or behavior of students in learning a subject matter[10]. Several countries had adopted OBE, like the USA, Australia, South Africa, Hong Kong, Malaysia, and European Union member countries. OBE believes providing learners the exact unit standards required to them, more significant buy-in support in the industry for there will be integration between education at school and the workplace.

Conversely, providing quality education in this current time evolves educators' teaching style that has gone through various transformations and in a high range. The 21 st-century students are capable of mastering skills in problem-solving, critical thinking, and digital literacy. Therefore, educators are now summoning to elevate teaching strategies to cope with the mandate of students' ever-changing learning styles. There are numerous emerging hallmarks of the teaching and learning method embedded in every educational institution representing their core values and teaching principles.

This study aims to identify the role of Outcomes-based Education in changing the landscape of higher education in South Korea through examining the correlation of Outcomes-based Education to student grade, teacher's performance, student knowledge of OBE, teacher's extent of knowledge and practice of OBE, and documentary analysis adopting the Outcomes-based education system in selected subject offerings in the International Commerce department of Keimyung University. Developing an outcome- 
based education framework as an instrument for educational change and served as a guide of the department in its readiness for the paradigm-shift to outcomes-based systems model of higher education in South Korea. The scope of this research covered faculty knowledge and understanding of OBE for a quality assurance mandated transition from traditional-based school to an outcomes-based model.

\section{Materials and Method}

\subsection{South Korea Educational System}

In South Korea, Education was noted by the Korean citizens for having high regard, for it constitutes to family's fame and fortune. Education served as a framework to check the access of Koreans to power through self-improvement. Since Korean independence, they had invested their wealth and soul in educating their children. As the Korean saying goes, "many dragons emerged from the sewage," people are moving towards obtaining diplomas as access for a brighter world.

Since 1954, South Korea had undergone seven significant revisions to "reflect the newly rising demands for education, emerging needs of a changing society, and new frontiers of academic disciplines" (Asia Society 2021). In 2013, the Ministry of Education introduced national Competency Standards (NCS) to identify and standardize the industry's competencies. It is an initiative to produce graduates that could compete globally about know-how as the product of a well-designed curriculum.

South Korea is known to be the most educated country in the world, according to the Organization for Economic Cooperation (OECD). 70 percent of 24-35 years old of their national population have completed tertiary education. The International Student Assessment (PISA) recognized South Korea as a top-quality school system measured by student performance.

However, the World Education News described South Korea's accentuating reputation for having the most ruthless education in the world. Students must devote more time to studying under pressure, authority, brutally competitive, and meritocratic (WES 2018). Several studies showed that South Korean students' emotional exhaustion was associated with academic inefficiency[11-13].

Despite the global educational system's success, South Korea has still faced challenges that surfaced from its achievements[14]. The challenges are related to students' low interest in learning, declining index of students' happiness, and increasingly deskilled teachers because of the prescribed curriculum. Several studies recommended that the South Korean educational system change school practices, teacher's professional development, socio-cultural reform, and quality of Education. Also, there is a high recommendation that the South Korean education system must improve the quantity and quality of active teacher-student interaction in the context of different classroom activities.

The latter recommendation characterized the student-learning center, which involves students in active participation responsibly at their phase. One of the principal goals that schools control the conditions that directly affect successful school learning. This assumption implies that implementers of OBE can direct and encourage all students to be successful learners.

Comparing the impact of OBE on the Korean Confucius style of teaching and use the OBE model was done to improve students' learning outcomes and professor's performance effectively. The idea of utilizing action research on the philosophy of Constructivism advocated by Jonassen 1991 is where the study, where the knowledge results from each individual's constructive activity, was acquired through strategies. Moreover, Constructivism can determine practical teaching strategies and learning opportunities where learners internalize new experiences and knowledge into their existing schema. Constructivist teaching practices was noted to help learners to internalize and reshape, or transform new information. 


\subsection{The Role of Outcomes-based Education in Changing the Educational Landscape}

The outcomes-based education is the total opposite of the traditional education method. It requires changing the emphasis on curriculum development and result-oriented assessment. In OBE, the students become the educational system's center, emphasizing the learner's skill and knowledge. As education moves towards the 21st Century, the educational bandwagon moves towards Outcomes-based Education (OBE). Academes change the education landscape from teacher-centered to student-center, which focuses on learners' future performance skills with knowledge applications achieving set learning outcomes.

Despite its popularity, OBE's adoption in Australian education in 1991, as the widespread influence of OBE defining characteristics of their curriculum, has been at the center of a good deal of public scrutiny and debate. The arguments are related to re-badging the curriculum and modifying the Essential Learning Curriculum's problematic aspects on its original design. Nevertheless, the US educationalist, William Spady, is a staunch advocate of OBE, and his works have had, and continue to have, a significant impact on Australia's adoption of OBE.

Education is a work in progress due to general global education and school leadership trends, encouraging institutions to use and develop new frameworks, amendments, or improvements[15].

OBE clearly defines student competency's intended final product in research study[16]. The outcomespecific outcome is used to plan the curriculum, monitor its implementation, evaluate it, and assess student's achievement. The research elaborates the steps for implementing outcomes-based education such as deciding on the outcome, demonstrating results, deciding on contents and teaching strategies, and assessment of OBE.

OBE believes to be an addition to the value of quality education where a specific outcome is defined. It also fosters multiple disciplines' active participation in planning designing curriculum content aligned with OBE standards and format. Besides, it encourages students to learn through various standardsreferenced assessments that convey effervescent descriptions of foreseen performance.

The variables used were OBE student grade (OSG), student extent of knowledge of OBE (SEK), teacher's extent of knowledge of OBE (TEK), Teachers' extent of knowledge of teaching method (TETM), teachers' performance (TP). OSG means the score of and grade of the student during the semester using the OBE method. The SEK is the extent of knowledge or understanding of OBE students as being used throughout the semester, while TEK understands and knows of the teacher of OBE. TETM is the teacher's knowledge of the OBE teaching method. TP is the teacher's performance evaluation throughout the semester.

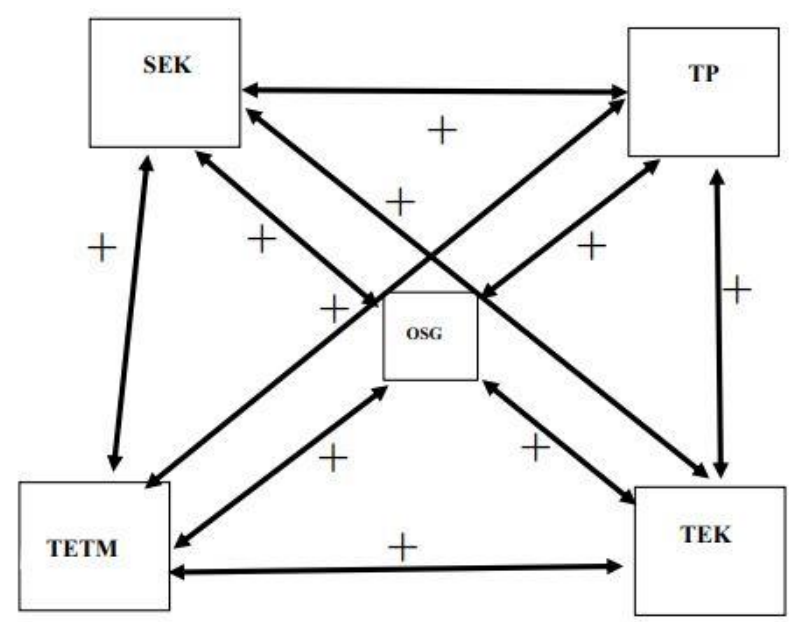

[Fig. 1] Hypothesized Model for Correlation of OBE Indicators 


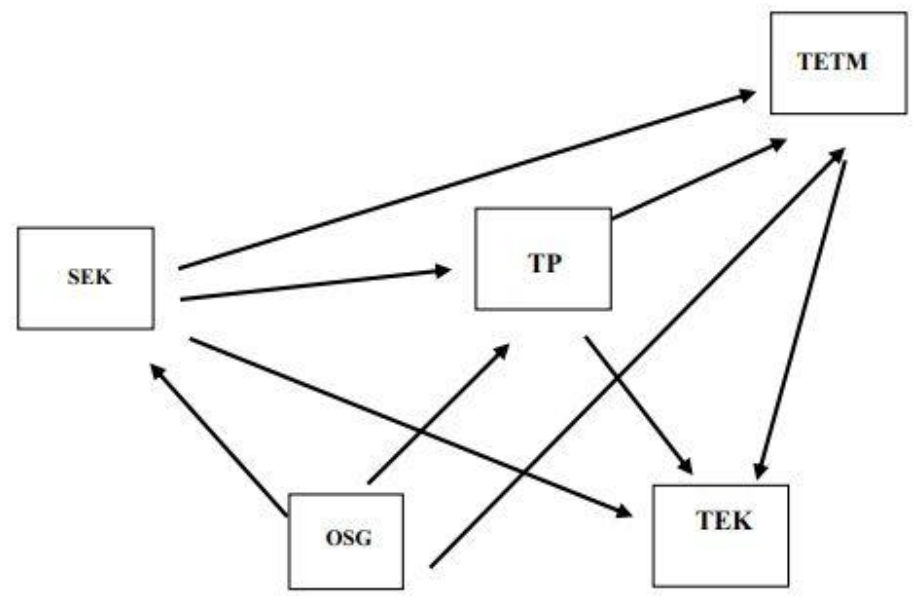

[Fig. 2] Hypothesized Model for Significant Relationship of OBE Indicators

Hypothesis:

$\mathrm{H}_{0} 1$ : OBE student grade (OSG), student extent of knowledge of OBE (SEK), teacher's extent of knowledge of OBE (TEK), Teachers' extent of knowledge of teaching method (TETM), and teachers 'performance (TP) has a positive correlation.

$\mathrm{H}_{0}$ 2: OBE student grade (OSG), student extent of knowledge of OBE (SEK), teacher's extent of knowledge of OBE (TEK), Teachers' extent of knowledge of teaching method (TETM), and teachers 'performance (TP) has no statistically significant relationship.

\subsection{Methodology}

Two hundred forty respondents participated in the survey, composed of students and professors in South Korea and the Philippines. This study adopted an experimental and descriptive research design utilizing the quantitative approach to identify the role of Outcomes-based Education in changing the landscape of higher education in South Korea through examining the correlation of Outcomes-based education to its indicators.

The data were collected from the respondents using questionnaires, interview guides, and achievement tests from the learners. The researcher collected students' grades by testing the four subject classes into two groups: the control and the experimental group. The control group receives the traditional teaching method, and the experimental group receives treatment by implementing the OBE system. Utilizing pretest and post-test helps to measure student's grades (OSG). The survey is adopted from the study "The essence of the outcomes-based education and knowledge of its implementation in Technological University in the Philippines"[17]. The researcher retrieved the teachers' performance (TP) from the semester's evaluation grade among courses taught. The weighted mean of the variables was processed using SPSS coefficient correlation to identify the significant correlation of each variable where $\leq 0.35$ low or weak correlation; 0.36 - to 0.67 - moderate positive correlation; 0.68 to 1.00 - strong positive correlation.

\section{Results and Discussion}

\subsection{Correlation of Extent of Knowledge of Students and Professor Performance in Implementation of Outcomes-based Education as Practiced in South Korea}


[Table 1] Correlations of OBE Student Grade, Student Extent of Knowledge of OBE, Teachers Performance, Teachers Extent of Knowledge of OBE and Extent of Teaching Method

\begin{tabular}{|c|c|c|c|c|c|c|}
\hline & & $\begin{array}{l}\text { OBE Student } \\
\text { grade }\end{array}$ & $\begin{array}{l}\text { Student extend } \\
\text { of knowledge }\end{array}$ & $\begin{array}{c}\text { Teachers } \\
\text { Performance }\end{array}$ & $\begin{array}{c}\text { Teacher } \\
\text { extent of } \\
\text { knowledge of } \\
\text { OBE } \\
\end{array}$ & $\begin{array}{l}\text { Teachers extent of } \\
\text { teaching method }\end{array}$ \\
\hline \multirow{3}{*}{ OBE Student Grade } & Pearson Correlation & 1 & .131 & .096 & .160 & $.234 *$ \\
\hline & Sig. (2-tailed) & & .203 & .353 & .119 & .022 \\
\hline & $\mathrm{N}$ & 96 & 96 & 96 & 96 & 96 \\
\hline \multirow{3}{*}{$\begin{array}{l}\text { Student extend of } \\
\text { knowledge }\end{array}$} & Pearson Correlation & .131 & 1 & .041 & $.560 * *$ & $.375^{* *}$ \\
\hline & Sig. (2-tailed) & .203 & & .690 & .000 & .000 \\
\hline & $\mathrm{N}$ & 96 & 100 & 96 & 100 & 100 \\
\hline \multirow{3}{*}{ Teachers Performance } & Pearson Correlation & .096 & .041 & 1 & -.055 & -.114 \\
\hline & Sig. (2-tailed) & .353 & .690 & & .592 & .268 \\
\hline & $\mathrm{N}$ & 96 & 96 & 96 & 96 & 96 \\
\hline \multirow{3}{*}{$\begin{array}{l}\text { Teachers extent of } \\
\text { knowledge of OBE }\end{array}$} & Pearson Correlation & .160 & $.560 * *$ & -.055 & 1 & $.475^{* *}$ \\
\hline & Sig. (2-tailed) & .119 & .000 & .592 & & .000 \\
\hline & $\mathrm{N}$ & 96 & 100 & 96 & 100 & 100 \\
\hline \multirow{3}{*}{$\begin{array}{l}\text { Teahcers extent of } \\
\text { knowledge of teaching } \\
\text { method }\end{array}$} & Pearson Correlation & $.234 *$ & $.375^{* *}$ & -.114 & $.475^{* *}$ & 1 \\
\hline & Sig. (2-tailed) & .022 & .000 & .268 & .000 & \\
\hline & $\mathrm{N}$ & 96 & 100 & 96 & 100 & 100 \\
\hline
\end{tabular}

*. Correlation is significant at the 0.05 level (2-tailed).

**. Correlation is significant at the 0.01 level (2-tailed).

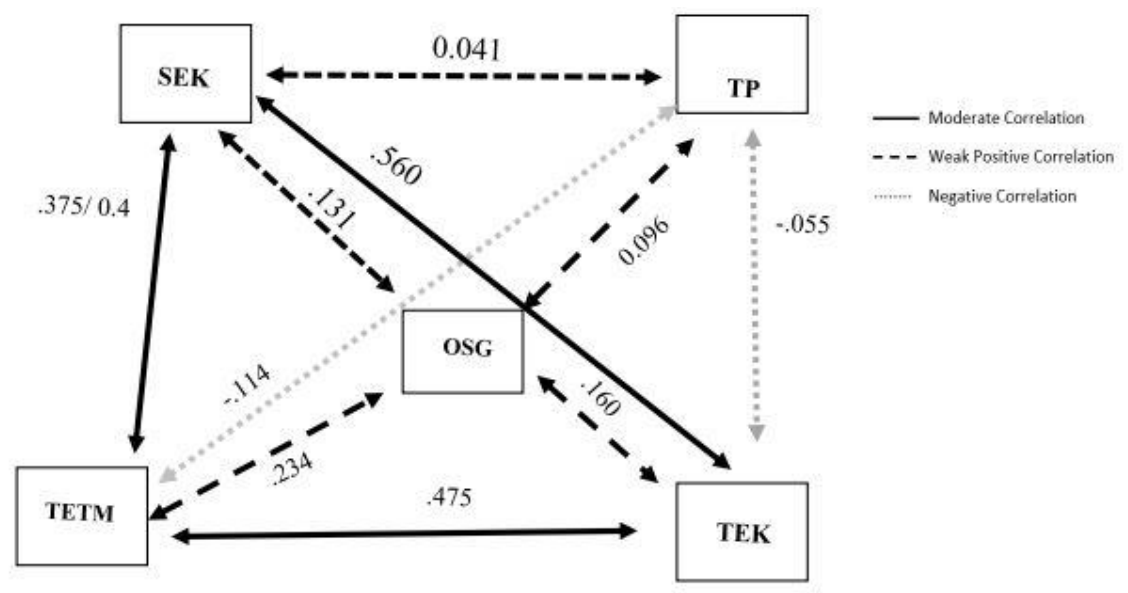

[Fig. 3] Pearson Coefficient Correlation of OBE Indicators Model

[Table 1] and [Fig. 3] show the Pearson Coefficient correlation of OBE indicators. OSG has a weak positive correlation with TETM (.234), TEK (.160), SEK (.131) and TP (.096). SEK has a weak positive correlation with OSG (.131), TP (0.041), moderate positive correlation with TEK (0.560) and TETM (0.40). TP has a negative correlation with TEK (-0.055) and TETM (-.114). TP has a weak positive correlation with OSG (0.096) and SEK (.041). TETM has a moderate positive relationship with TEK (.475). TEK has a weak positive relationship with OSG (.160) and a moderate positive correlation with SEK (.560) and TETM (.475). TEK a negative correlation with TP (-.055). TETM has a weak positive relationship with OSG (.234), a moderate positive relationship with SEK (.375), a negative correlation with TP (-.114), moderate positive correlation with TEK (.475).

The hypothesis framework modelling reveals the degree of correlation of each OBE indicators. The result affirms the theory of Sassums and Spady that OBE can lead students demonstrate proficiency of skills, knowledge, and behavior. It shows that understanding the instructional strategies has a significant contribution to student learning interest[18]. Students who are taught by teachers with high-performance 
ratings are likely to achieve better grade and can effectively utilize the material. It implies that student grade was substantially affected by OBE instructional strategy.

Moreover, it reveals that teacher's performance has a negative correlation with teachers' extent of knowledge of OBE and extent of knowledge of teaching method. There are several studies affirm that teacher's effectiveness has no correlation with teacher's performance rating using teacher evaluation instrument standards demonstration. American Federation of Teachers (2011) has mentioned that there is no single instrument that could accurately assess teacher's effectiveness. There is a continuous development of theories related to effective learning which prompt the necessity to improve the measurement standards of teacher performance. Nevertheless, it was a believe that the role of teacher's performance directly contributes to school effectiveness to achieve their educational objectives[19].

\subsection{Significant Relationship of OBE Indicators}

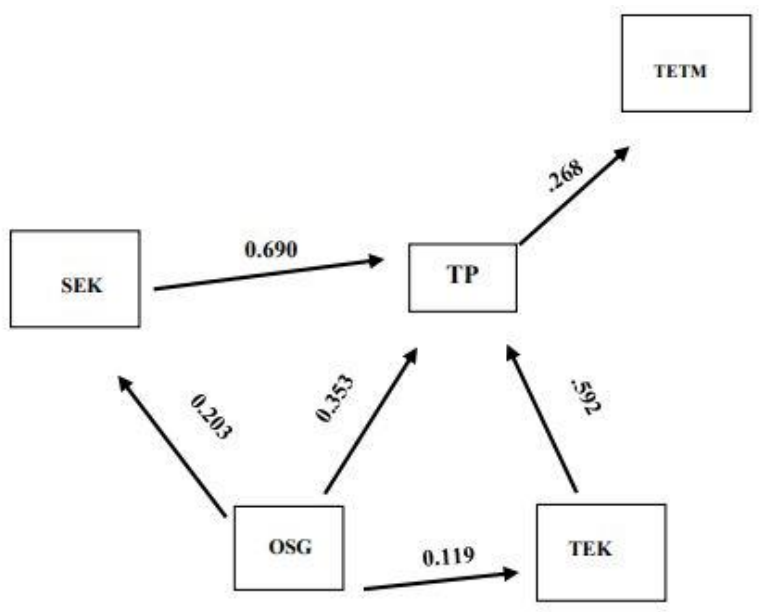

[Fig. 4] Significant Relationship among OBE Indicators Models

[Fig. 4] shows the significant relationship among OBE indicators. The model had shown that OSG (.203), TP (.353), TEK (.119), SEK (.690), TEK (.592), and TETM (.268) is not statistically significant. However, the OSG and TETM (0.022), SEK and TEK (0.000), SEK and TETM (0.000), and TETM and TEK $(0.000)$ are statistically significant, which rejects the null hypothesis two.

The motivation of student to perform well in the classroom has a significant relationship with the understanding of teachers in delivering the learning process and materials. Pedagogical knowledge and content are two important components of teaching that motivate and support student learning according[20]. More so, understanding the style of teaching by student draws an intervention to the confusion of teaching method to be implemented. Assessing student's knowledge of OBE can support teacher's skill to design and apply the learning process appropriately. The result implies that extent of knowledge of OBE can maximize the learning capacity of students and enhance the pedagogical competence of teacher.

[Table 2] Model Summary

\begin{tabular}{cc|ccc}
\hline Model & R & R Square & Adjusted R Square & Std. Error of the Estimate \\
\hline 1 & $.271 \mathrm{a}$ & .073 & .033 & 8.18914 \\
\hline
\end{tabular}

[Table 2] shows that the correlation coefficient value $\mathrm{r}=.271(27 \%)$ is more significant than 0.05 , indicating the probability that $\mathrm{Ho} 1$ is true. It shows the positive relationship between OBE student grade and student extent of OBE knowledge, teacher's performance, teacher's extent of OBE knowledge, and 
teaching method. The R Square value of $7.3 \%(.073)$ of the variation is shown in the table during the OBE processed. Therefore, the Hol is accepted.

[Table 3] Analysis of Variance (ANOVA) of Student Grades among Extent of Knowledge of OBE, Teachers Performance and Method of Teaching.

\begin{tabular}{ccccccc}
\hline & Model & Sum of Squares & df & Mean Square & F & Sig. \\
\hline \multirow{2}{*}{1} & Regression & 482.350 & 4 & 120.587 & 1.798 & $.136 \mathrm{~b}$ \\
& Residual & 6102.640 & 91 & 67.062 & & \\
& Total & 6584.990 & 95 & & & \\
\hline
\end{tabular}

[Table 3] shows the Analysis of variance in OBE Student grades among student extent of OBE knowledge, teacher's performance, teacher's extent of OBE knowledge, and teaching method. The result confirms to accept the Hol that there is no statistically significant difference between student grade, student extent of OBE expertise, teacher's performance, teacher's extent of OBE knowledge, and teaching method.

Using ANOVA and Pearson Coefficient correlation, the result manifested the impact of OBE with student grades, teacher's extent of knowledge of OBE, teaching method and student knowledge of the instructional strategy. The result denotes that outcomes-based learning and assessment approaches comprise effective mechanisms for improving the educational experiences of students and a useful tool for teachers and course programs, to obtain better results in terms of student learning outcomes.

\subsection{Korea Educational System}

Korean Professors are known traditionally to have an authoritarian attribute in terms of teaching students. Korean educational system has emerged as the world number one for educating students. Taoism, Confucianism, and Buddhism influenced Korea's culture and were the pillars behind character formation and education. Until 19, learning no longer takes place as effectively as before in most current Korean classrooms. South Korea had experienced a "school collapse," which describes schools' situations where students' level of interest and enthusiasm for learning school reduced its level. Notably, students became destructed and shrunk participating in classroom activities.

According to many Korean researchers, the (3) factors contribute to classroom breakdown, generally in Korea. These are: first being the limitations of schooling in not effectively coping with the new era of information technology and a consumption-oriented culture, second being the clash between generations and between youth culture and school culture, and third being recent unsuccessful education policies resulting in a deterioration of teachers' authority and teachers' control over students.

With the heightened caveat of the impact of this "school collapse" and several research indications, students could not choose what they wanted to learn in school. The Korean government has already realized the importance of students' input in their learning process to nurture their creativity and thus initiated reforms to the school curriculum to enable students to choose the subjects they want to learn. The Ministry of Education announced the new 7th National Curriculum first implemented in schools in 2003. This student-centered curriculum is aiming to facilitate students' autonomy and creativity. The policymakers perceived the two focal characteristics of independence and creativity as two of the essential abilities required for leadership in the 21 st-century era of globalization and information technology.

In the situation at Keimyung University, professors were using different strategies to involve their student's in the learning process by providing them an avenue to present their knowledge and skills. But 
this is not absolutely true to all because there are still professors wedged on their traditional teaching method.

The researcher interviewed professors at Keimyung University concerning their extent of knowledge and implementation of OBE and the common issues they encounter in teaching. Most of them derived it as the constructivism method. They mentioned that OBE could provide a clear direction of what the students ought to learn and evaluate them according to what they can do. One professor said that it is advantageous for the teacher and students to ensure learning objectives and learning outcomes. Also, it provides students freedom on how they want to understand the lesson and demonstrate learning in the most convenient way it could be. The professor emphasized that the syllabus must be tailored to the students' learning capacity to implement OBE, including identification expertly. Another professor mentioned that the students should be aware of what teaching strategy that the professor will adopt so that they will not be disturbed by the unfamiliar learning setting of OBE. Students were still in the notion of traditional classroom learning. Therefore, the enlightenment of $\mathrm{OBE}$ is one of the crucial aspects. The curriculum must be according to the framework of OBE and align the activities and evaluation method with

Another professor added that OBE is proper, but it requires much preparation on the part of teachers, and a class hour sometimes is not sufficient to accomplish the activity. Another professor confirmed that it is essential to determine an appropriate action that encourages students to participate and challenge them to perform excellently. More so, a substantial amount of required work for planning, designing, and developing a learning program. One professor said, "It seems that the students understand the subject better, and they were happy with the given dynamic activities."

Most interviewees reported positive perceptions of OBE as an effective method to strategizing the learning process and measure performance following the desired outcomes. They understood that OBE helps facilitate their students' learning while promoting an interactive education inside the classroom. A seminar-workshop was mentioned to help professors lift classroom management and prepare lessons as a rat race of the academe. Therefore, it was evident that the OBE system promotes quality education, which unveils a student's professional knowledge, skills, abilities, values, and attitude. Likewise, it provides an opportunity for the students to understand and learn better as it focuses on the outcomes.

\section{Conclusion}

This paper aimed to identify the role of Outcomes-based education (OBE) in changing the educational landscape through correlating student grade, extent of knowledge, teaching method and teacher's performance to develop an outcomes-based systems model for higher education. Based on the regression correlation model, the student output has a correlation to all predictors of OBE. More so, OBE could play an important role in changing the landscape of higher education in South Korea. The results of the study were evidence that OBE curriculum is an effective method of teaching because it provides students with unlimited opportunities to demonstrate the mastery of contents taught. In conclusion, the action study result shows that OBE can significantly improve the learning effectiveness of students and teaching quality.

Based on the preliminary conclusion, this study recommends the development and adaptation of an outcome-based framework towards designing research and development-oriented OBE curriculum for the International Commerce Department of Keimyung University.

\section{References}

[1] J. S. Armstrong, Natural Learning in Higher Education. In N. M. Seel (Ed.), Encyclopedia of the Sciences of Learning 
1 (pp. 5-10). Heidelberg: Springer, (2012).

[2] G. E. Dehler, M. A. Welsh, Against spoon-feeding. For learning. Reflections on students' claims to knowledge, Journal of Management Education, (2014), Vol.38, No.6 pp.875-893.

[3] J. Soliman, Student Centered Instruction for Interactive and Effective Teaching Learning: Perceptions of Teachers in Bangladesh, International Journal of Advanced Research in Education and Technology, (2016), Vol.3, No.3, pp.172178.

[4] T. Burner, Formative assessment of writing in English: A school-based study of perceptions, practices, and transformations, NTNU, Doctoral Dissertation, (2016)

[5] M. B. Postholm, Teachers' professional development: a theoretical review, Educational Research, (2012), Vol.54, No.4, pp.405-429, DOI:10.1080/00131881.2012.734725

[6] A. Hargreaves, M. Fullan, Professional Capital: Transforming Teaching in Every School, Teachers College Press, (2012)

[7] P. S. Aithal, P. M. Kumar, Student Performance and Learning Outcomes in Higher Education Institutions, International Journal of Scientific Research and Modern Education, (2016), Vol.1, No.1, pp.674-684.

[8] B. M. Hejazi, Outcomes-Based Education (OBE): A Transformational Perspective on Quality and Mobility in Higher Education, Community College Leadership Program, (2011), pp.1-30, http://www.jfn.ac.lk.

[9] J. M. Laguador, D. I. Dotong, Knowledge versus Practice on the Outcomes-Based Education Implementation of the Engineering Faculty Members in LPU, International Journal of Academic Research in Progressive Education and Development, (2014), Vol.3, No.1, pp.63-74, DOI: 10.6007/IJARPED/v3-i1/640

[10] Sessums, What is OBE? Unboxing Outcomes-bases Education, (2016), Retrieved From http://www.d2l.com>Blog

[11] M. Y. Lee, M. K. Lee, M. J. Lee, S. M. Lee, Academic Burnout Profiles and Motivtion Styles Among Korean High School Students, The Japanese Psychological Research, (2020), Vol.62, No.3, pp.184-195, https://doi.org/10.1111/jpr.12251

[12] Y. M. Park, S. M. Lee, A longitudinal analysis of burnout in middle and high school Korean teachers, Stress Health, (2013), Vol.29, No.5, pp.427-431, DOI: 10.1002/smi.2477

[13] J. Cho, M. S. Kim, Development and Validation of Korean Academic Burnout Scale for Elementary School Students, Family and Environment Research, (2014), Vol.52, No.1, pp.43-53, DOI: https://doi.org/10.6115/fer.2014.52.1.43

[14] K. So, J. Kang, Curriculum Reform in Korea: Issues and Challenges in the Twenty-first Century Learning, The AsiaPacific Education Researcher, (2014), Vol.23, No.4, pp.795-803, DOI:10.1007/s40299-013-0161-2

[15] E. J. Pattaguan, To Be on Top: A Sustained Outcomes-Based Accountancy Education Experience, Journal of Business Studies Quarterly, (2016), Vol.7, No.3, pp.127-151.

[16] R. Eldeeb, N. Shatakumari, Outcome-Based Education (OBE) - Trend Review, Department of Physiology, Gulf Medical University (GMU), IOSR Journal of Research \& Method in Education (IOSR-JRME), (2013), Vol.1, No.2, pp.9-11.

[17] M. De Guzman, D. Edaño, Z. Umayan, Understanding the Essence of the Outcomes-Based Education (OBE) and Knowledge of its Implementation in a Technological University in the Philippines, Asia Pacific Journal of Multidisciplinary Research, (2017), Vol.5, No.4, pp.64-71.

[18] A. Omori, O. A. Edem, E. M. Obun, Instructional Strategy and Teacher-student Relationships as Predisposing Variables of Adult Students' Learning Interest in the Universities, International journal for innovation education and research, (2019), Vol.7, No.5, pp.123-132, DOI: https://doi.org/10.31686/ijier.vol7.iss5.1483

[19] M. Ozgenel, P. Mert, The Role of Teacher Performance in School Effectiveness, International Journal of Education Technology and Scientific Research, (2019), Vol.4, No.10, pp.417-434.

[20] I. Maryani, S. T. Martaningsih, Correlation between Teacher's PCK (Pedagogical Content Knowledge) and Student's Motivation in Primary School in Indonesia, International Journal of Evaluation and Research in Education, (2015), Vol.4, No.1, pp.38-44, DOI: http://doi.org/10.11591/ijere.v4i1.4490 